\title{
Methylation of CLDN6, FBN2, RBP1, RBP4, TFPI2, and TMEFF 2 in esophageal squamous cell carcinoma
}

\author{
SHIGERU TSUNODA ${ }^{1,2}$, ERIC SMITH ${ }^{1}$, NEVILLE J. DE YOUNG ${ }^{1}$, XIAN WANG $^{1}$, \\ ZI-QING TIAN ${ }^{3}$, JUN-FENG LIU ${ }^{3}$, GLYN G. JAMIESON ${ }^{1}$ and PAUL A. DREW ${ }^{4}$ \\ ${ }^{1}$ Discipline of Surgery, The University of Adelaide, Adelaide, South Australia 5005, Australia; \\ ${ }^{2}$ Department of Surgery, Graduate School of Medicine, Kyoto University, Kawaracho 54, Shogoin, Sakyo-ku, \\ Kyoto 606-8507, Japan; ${ }^{3}$ Department of Thoracic Surgery, 4th Hospital of Hebei Medical University, Hebei, Shijiazhuang \\ 050011, P.R. China; ${ }^{4}$ School of Nursing and Midwifery, Flinders University, Bedford Park, South Australia 5042, Australia
}

Received October 27, 2008; Accepted November 28, 2008

DOI: 10.3892/or_00000325

\begin{abstract}
In the development and progression of cancer, tumor suppressor genes may be silenced by mechanisms such as methylation. Thus the discovery of new genes silenced by methylation may uncover new tumor suppressor genes, and improve our understanding of cancer biology. In this study we investigated the methylation of 19 genes in esophageal squamous cell carcinoma. Methylation was measured in 10 of these genes in esophageal squamous cell carcinoma cell lines: CDH13, CLDN6, C16orf62, FBN2, FNBP1, ID4, RBP1, RBP4, TFPI2 and TMEFF2. To determine if there was a correlation between DNA methylation and gene silencing, each cell line was cultured with or without the demethylating drug 5-aza-2'-deoxycytidine (aza-dC). For 6 genes (CLDN6, FBN2, RBP1, RBP4, TFPI2 and TMEFF2) there was an association between reduction of methylation and increase in mRNA expression in the demethylated cell lines. The frequency of the methylation of these 6 genes in esophageal squamous cell carcinoma resection specimens was also investigated. All 6 genes showed more frequent methylation in the tumor than the matched proximal resection margin of uninvolved esophagus. There was a significant difference in the frequency of methylation and in the extent of the methylation between the cancer and the margin tissues for CLDN6, FBN2, TFPI2 and TMEFF2 $(\mathrm{P}=0.0007, \mathrm{P}=0.0048$ $\mathrm{P}=0.0002$ and $\mathrm{P}<0.0001$, respectively). This is the first report of gene silencing by methylation of CLDN6, FBN2, RBP4, TFPI 2 and TMEFF 2 in esophageal squamous cell carcinoma.
\end{abstract}

Correspondence to: Dr Shigeru Tsunoda, Discipline of Surgery, The University of Adelaide, Adelaide, South Australia 5005, Australia

E-mail: tsunoda@kuhp.kyoto-u.ac.jp

Key words: esophageal cancer, methylation, CLDN6, FBN2, RBP1, RBP4, TFPI2, TMEFF2

\section{Introduction}

Esophageal cancer is one of the most lethal of malignancies and worldwide is the sixth most common cause of death from cancer (1). Despite many refinements in surgery, chemotherapy, radiotherapy, and combined therapy, the 5-year survival rate remains around $10 \%$ (2). The two most common histological types of esophageal cancer are squamous cell carcinoma and adenocarcinoma. While there has been a recent, rapid increase in the incidence of adenocarcinoma in Western countries, including Australia (3-6), squamous cell carcinoma remains the most common form of esophageal cancer worldwide. Understanding the molecular pathology of such cancer may advance therapeutic and diagnostic strategies for these clinically important cancers.

The development and progression of esophageal squamous cell carcinoma is described as a multistep process, with a transition from normal to a hyperproliferative squamous epithelium, and then through low-, intermediate- and high-grade dysplasia/carcinoma in situ to invasive carcinoma. Through these sequential pathological changes there is an increasing atypia compared to normal squamous epithelium, and an increasing risk for the development of esophageal squamous cell carcinoma (7). Although the histological progression of esophageal squamous cell carcinoma is relatively well established, our knowledge of the molecular events which parallel or underlie this progression is more limited, especially in terms of activation of oncogenes or inactivation of tumor suppressor genes. The changes in cellular phenotype are thought to result from the dysregulation of gene expression and/or protein function, attributable to genetic and/or epigenetic changes. A common epigenetic change which can cause transcriptional silencing of genes, including tumor suppressor or growth-regulatory genes, is methylation of $\mathrm{CpG}$ islands associated with the promoter region of these genes (8). Detection of methylation of $\mathrm{CpG}$ islands may reveal novel tumor suppressor genes, and provide insights into the underlying tumor biology.

In a previous study we discovered 19 new genes commonly silenced by methylation in esophageal adenocarcinoma $(9,10)$. To broaden our understanding of the importance 
Table I. The summary of primers used in this study.

\begin{tabular}{|c|c|c|c|}
\hline Gene & Forward primer $\left(5^{\prime}>3^{\prime}\right)$ & Reverse primer $\left(5^{\prime}>3^{\prime}\right)$ & $\begin{array}{l}\text { Annealing } \\
\text { temperature }\end{array}$ \\
\hline \multicolumn{4}{|c|}{ Methylation } \\
\hline BNIP3 & TYGGTTTYGTTTTGTTTTGTGAGTTTT & CCRAACTACRAAATATACTTCAACTA & 55 \\
\hline CDH13 & GATTTATTTGGGAAGTTGGTTGGT & CRAAATTCTCRACTACATTTTAT & 55 \\
\hline CLDN6 & AGGYGGGTTTAGYGATTTTAGTT & AATTCCTAAACCRAATATCRAAACAAA & 55 \\
\hline C16orf62 & GTTAGTTGAAAATGAAGTTTGTGT & CCRCCATATTTATAAAAAACAACTAA & 55 \\
\hline DCBLD2 & GGGTGGGAYGTTTTTAAAGGT & ACCAATCCTCRACCAACTCTAA & 55 \\
\hline FBN2 & TYGTTYGGTTTYGTAGTYGTTAT & CRAATATTAAAAAACTACAAAAATCACCAA & 55 \\
\hline FNBP1 & GTTGTTAGGGGAAAGTATTGTTT & AATAATAACTTCTTAATAACCACTATCTA & 55 \\
\hline ID4 & GGGGYGTAYGGTTTTATAAATATAGTTG & TAATCACTCCCTTCRAAACTCCRACTAAA & 55 \\
\hline MLF1 & GAGTAATGTTTAATGGGAAAGTAGT & САТССТАААСАТТСТААСТСТАТСТТА & 55 \\
\hline NRG1 & GTGYGAAGGAGGYGTTTGTTT & CCRCCRCTCAACTCCTAA & 57 \\
\hline PRDM2 & GAATTTTTGAATTAYGTAGGATTTTAGT & CССААТААССАССАСССАA & 60 \\
\hline RBP1 & TGTGYGYGTTGGGAATTTAGTTG & CRAAAAATAACTAAAACCAATTAACCACAAA & 55 \\
\hline RBP4 & TTAGGGYGYGTTATGTAAGTGTT & AAAAAAACCRCRCRCAAACCTAA & 54 \\
\hline RUNX3 & YGTYGTTTTTTGYGTTTTGAGGTT & ACTTAAATCTACRAAAATACRCATAACAA & 55 \\
\hline TFAP2C & GGGGAGGAGTTATGATAATTTTT & AACCTTACTATCCRAATCACTAA & 55 \\
\hline TFPI2 & GTATTYGGGTYGTTTGGAGT & TCCTAAACAACATCRCCCAATA & 57 \\
\hline TIAM1 & GTTTTGATAGTTTYGATTGGTAGATT & ACRAAACAACCRTACCCCTAA & 59 \\
\hline TMEFF2 & TTGTTTTTTYGTYGGGTGTTATTGTTAT & AACAAACRACTTCCRAAAAACACAAA & 55 \\
\hline VGLL3 & GAAGGTGTTYGYGTATGGGT & CCRCAACTACCRCCTCTAT & 57 \\
\hline \multicolumn{4}{|l|}{ qPCR } \\
\hline $\mathrm{CDH} 13$ & AATCCACAAACAAGCTGTTCC & GTTTCCCTGAATCTGTCACCA & 57 \\
\hline CLDN6 & CTTCGCAGTGCAGCTCCTT & ACAGGAGACCAGGCCATTC & 57 \\
\hline C16orf62 & AGCTGTGTGAGACGGTGATG & GTTGAGCTTGTTGTTGCGTAG & 57 \\
\hline FBN2 & TGGATTTTGTTCCCGTCCTA & CCACCATTCATGCATCTCAC & 55 \\
\hline FNBP1 & TGCAAAGCAACTCAGGAATCT & TTCATTTCGTTCAGGTTGGAA & 57 \\
\hline ID4 & CCGAGCCAGGAGCACTAGAG & CTTGGAATGACGAATGAAAACG & 60 \\
\hline RBP1 & AGGCATAGATGACCGCAAG & CTCATCACCCTCGATCCAC & 62 \\
\hline RBP4 & CTTTCTGCAGGACAACATCG & TCCTCGGTGTCTGTGAAGGT & 59 \\
\hline TFPI2 & GTCGATTCTGCTGCTTTTCC & CAGCTCTGCGTGTACCTGTC & 60 \\
\hline TMEFF2 & CAATGGGGAGAGCTACCAGA & TGGACTCCATCTCCAGATCC & 62 \\
\hline HMBS & ACATGCCCTGGAGAAGAATG & TTGGGTGAAAGACAACAGCA & 57 \\
\hline
\end{tabular}

of these genes in cancer we have measured their methylation in esophageal squamous cell carcinoma cell lines and in tissues resected from patients with esophageal squamous cell carcinoma.

\section{Materials and methods}

Cell cultures. Triplicate cultures of the esophageal squamous cell carcinoma cell line OE21 were grown in RPMI-1640, supplemented with $10 \%$ fetal bovine serum (FBS), at $37^{\circ} \mathrm{C}$ in air with $5 \% \mathrm{CO}_{2}$. Triplicate cultures of the esophageal squamous cell carcinoma cell lines KYSE-170, KYSE-510, KYSE-1170 $(11,12)$ were grown in Ham's F-12/RPMI-1640 with $2 \% \mathrm{FBS}$ at $37^{\circ} \mathrm{C}$ in air with $5 \% \mathrm{CO}_{2}$, and $\mathrm{SUm} / \mathrm{c}(12)$ the same except for $5 \%$ FBS.

Demethylation of esophageal squamous cell carcinoma cell lines by aza-dC treatment. The cell lines were seeded into flasks and cultured for $24 \mathrm{~h}$, and then for a further $72 \mathrm{~h}$ in culture medium to which had been added either vehicle or $1 \mu \mathrm{M}$ aza-dC (Sigma-Aldrich, St. Louis, MO, USA) as previously described (13). Preliminary experiments showed that these conditions were sufficient for at least two cell divisions. The cells were then cultured for a further $24 \mathrm{~h}$ in fresh medium without aza-dC or vehicle before harvesting.

Patients and surgical specimens. Tumor and corresponding uninvolved squamous epithelium from the proximal resection margin were obtained from patients who had had an esophagectomy for primary esophageal squamous cell carcinoma at the 4th Hospital of Hebei Medical University, Shijiazhuang, P.R. China. The tissues were collected into RNAlater (Ambion, Austin, TX, USA). Informed consent was obtained from the patients for the use of the resected samples for research. The study complied with the appropriate institutional guidelines. 
Table II. The methylation status of studied 19 genes in esophageal squamous carcinoma cell lines.

\begin{tabular}{|c|c|c|c|c|c|}
\hline & KYSE-170 & KYSE-510 & KYSE-1170 & $\mathrm{SUm} / \mathrm{c}$ & OE21 \\
\hline BNIP3 & $\mathrm{U}$ & $\mathrm{U}$ & $\mathrm{U}$ & $\mathrm{U}$ & $\mathrm{U}$ \\
\hline CDH13 & M & M & M & M & M \\
\hline CLDN6 & $\mathbf{M}$ & $\mathbf{M}$ & $\mathbf{M}$ & M & $\mathbf{M}$ \\
\hline C16orf62 & M & M & M & M & $\mathrm{U}$ \\
\hline DCBLD2 & $\mathrm{U}$ & U & $\mathrm{U}$ & $\mathrm{U}$ & $\mathrm{U}$ \\
\hline FBN2 & $\mathbf{M}$ & $\mathbf{M}$ & $\mathrm{U}$ & $\mathrm{U}$ & $\mathrm{U}$ \\
\hline FNBP1 & M & $\mathrm{U}$ & M & $\mathrm{U}$ & U \\
\hline ID4 & $\mathrm{U}$ & U & $\mathrm{U}$ & M & U \\
\hline MLF1 & U & U & $\mathrm{U}$ & $\mathrm{U}$ & U \\
\hline NRG1 & $\mathrm{U}$ & $\mathrm{U}$ & $\mathrm{U}$ & $\mathrm{U}$ & $\mathrm{U}$ \\
\hline PRDM2 & $\mathrm{U}$ & U & $\mathrm{U}$ & $\mathrm{U}$ & U \\
\hline RBP1 & M & M & M & $\mathrm{U}$ & $\mathbf{M}$ \\
\hline RBP4 & $\mathbf{M}$ & M & M & $\mathrm{U}$ & $\mathrm{U}$ \\
\hline RUNX3 & $\mathrm{U}$ & $\mathrm{U}$ & $\mathrm{U}$ & $\mathrm{U}$ & $\mathrm{U}$ \\
\hline TFAP2C & $\mathrm{U}$ & $\mathrm{U}$ & $\mathrm{U}$ & $\mathrm{U}$ & U \\
\hline TFPI2 & M & M & M & $\mathrm{U}$ & U \\
\hline TIAM1 & $\mathrm{U}$ & $\mathrm{U}$ & $\mathrm{U}$ & $\mathrm{U}$ & $\mathrm{U}$ \\
\hline TMEFF2 & $\mathbf{M}$ & $\mathbf{M}$ & M & M & M \\
\hline VGLL3 & $\mathrm{U}$ & U & $\mathrm{U}$ & $\mathrm{U}$ & $\mathrm{U}$ \\
\hline
\end{tabular}

Extraction and bisulphite modification of genomic DNA. The methods used for the preparation of genomic DNA and its bisulphite modification have been reported previously (13-15). Briefly, TRIzol (Invitrogen Inc., Calsbad, CA, USA) was used to extract genomic DNA from the cell lines or proteinase K digested tissues (16). Then $2 \mu \mathrm{g}$ of genomic DNA was denatured by treatment with $\mathrm{NaOH}$ at $37^{\circ} \mathrm{C}$ for $15 \mathrm{~min}$. This was then modified using a mixture of $5 \mathrm{M}$ sodium bisulphite (Sigma-Aldrich) and $0.72 \mu \mathrm{M}$ hydroquinone (Sigma-Aldrich) for $4 \mathrm{~h}$ at $56^{\circ} \mathrm{C}$. The samples were purified using UltraClean PCR Clean-up kit (MO BIO Laboratories, Inc., Carlsbad, CA, USA), desulfonated with $\mathrm{NaOH}$ for $15 \mathrm{~min}$ at $37^{\circ} \mathrm{C}$, precipitated with ethanol and sodium acetate, and finally resuspended in $100 \mu 1$ of Ultra Pure Water (Fisher Biotec Australia, Wembley, WA, Australia).

Measurement of DNA methylation. DNA methylation analysis was performed as described previously (15). Briefly, bisulphite modified DNA was amplified with primers and PCR conditions which did not discriminate between methylated and unmethylated sequences and did not amplify unmodified DNA. The primers and annealing temperatures are summarized in Table I. The PCR was carried out using a Rotor-Gene 3000 (RG3000, Corbett Life Science, Mortlake, NSW, Australia) in a $15 \mu \mathrm{l}$ reaction volume containing $5 \mu 1$ of water, $0.75 \mu 1$ of each $10 \mu \mathrm{M}$ primers, $7.5 \mu 1$ of $2 \mathrm{X}$ QuantiTect SYBR-Green PCR Master Mix (Qiagen Gmbh, Hilden, Germany) and $1 \mu 1$ of bisulphite modified DNA. Reactions were started by initial denaturation at $95^{\circ} \mathrm{C}$ for $15 \mathrm{~min}$, followed by 45 cycles each of $20 \mathrm{sec}$ at $95^{\circ} \mathrm{C}$ then $45 \mathrm{sec}$ for annealing and extension. The PCR was finished with a final extension at $72^{\circ} \mathrm{C}$ for 4 min. Melt curve analysis was performed immediately after amplification by measuring the reduction in the fluorescence of the SYBR-Green I during a linear temperature transition from $60^{\circ} \mathrm{C}$ to $95^{\circ} \mathrm{C}$ at a rate of $0.5^{\circ} \mathrm{C} / \mathrm{sec}$. The $-\mathrm{dF} / \mathrm{dT}$ curves were generated from the fluorescence data using RG3000 application software version 6.0. Bisulphite modified DNA from lymphocytes of healthy donors was used for the unmethylated control, and $\mathrm{CpG}$ methylase (M.Sss1, New England Biolabs Inc., Ipswich, MA, USA) treated lymphocyte DNA for the methylated control. The extent of methylation was assessed from the $-\mathrm{dF} / \mathrm{dT}$ curves using our standard protocol. Briefly, a curve which was almost identical to the methylated control was scored as $3+$, a curve whose melting temperature was closer to methylated control than the unmethylated control was scored as $2+$, a curve which was almost identical to unmethylated control was scored 0 , and the rest were scored as $1+$. All assessment was undertaken independently by two investigators (S.T. and E.S.) and, if their opinions differed, consensus was reached by discussion.

Measurement of gene expression by quantitative reverse transcription-PCR. Total RNA was extracted from cell lines by TRIzol, and treated with the TURBO DNA-free Kit (Ambion). The concentration of the RNA was measured spectrophotometrically using the ND-1000 (NanoDrop Technologies, Wilmington, DE, USA). The cDNA was synthesized from the RNA using the SuperScript II FirstStrand Synthesis System for RT-PCR (Invitrogen Inc.) according to the manufacturer's instruction. Quantitative real-time reverse transcription-PCR (qPCR) was performed 
(a)
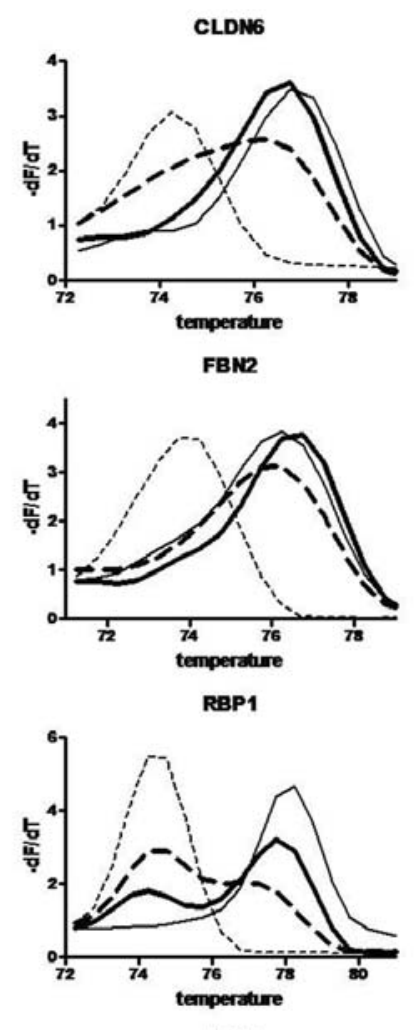

RBP4

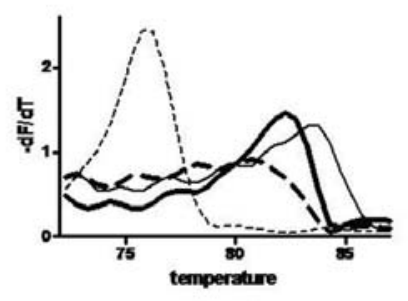

TFP2

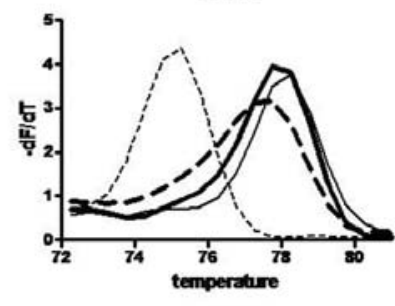

TUEFF2

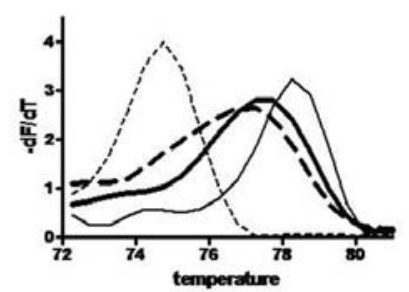

(b)
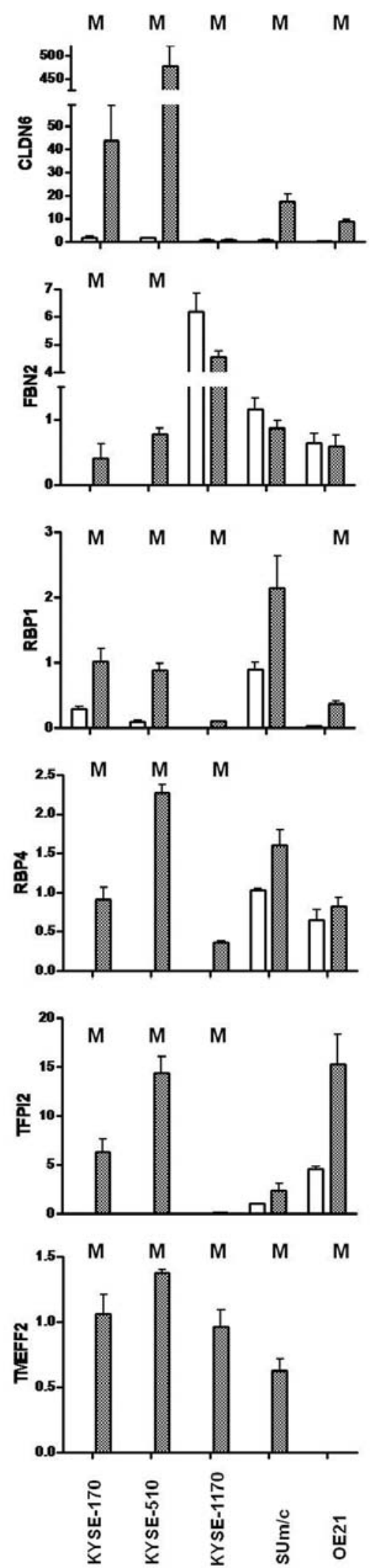

Figure 1. Methylation and expression of CLDN6, FBN2, RBP1, RBP4, TFPI2 and TMEFF2 in esophageal squamous cell carcinoma cell lines. (a) Methylation in the esophageal squamous cell carcinoma cell line KYSE-170 cultured with either aza-dC or vehicle. Bisulphite modified DNA was amplified using primers and PCR conditions (Table I). These were specific for bisulphite modified DNA, did not discriminate between methylated and unmethylated sequences, and did not amplify unmodified DNA. The PCR products were melted by increasing the temperature from 60 to $95^{\circ} \mathrm{C}$, rising $0.5^{\circ} \mathrm{C}$ at each step, waiting $30 \mathrm{sec}$ on the first step then $5 \mathrm{sec}$ for each step thereafter. Data were collected and analyzed using the Melt Curve Analysis function of the RG3000 application software. The melt curves for unmethylated (light dotted line) and methylated (light solid line) controls and cell lines treated with vehicle (dark solid line) or aza-dC (dark dotted line) are shown. The horizontal axis represents temperature and the vertical axis - $\mathrm{dF} / \mathrm{dT}$. (b) Gene expression in 5 esophageal squamous cell carcinoma cell lines treated either with aza-dC (shaded bar) or with vehicle (white bar). The normalized relative expression of the gene of interest was determined by dividing by the expression of the housekeeping gene HMBS. A white bar shows vehicle treatment and a shaded bar shows aza-dC treatment. An M indicates a cell line in which methylation was measured. 
(a)
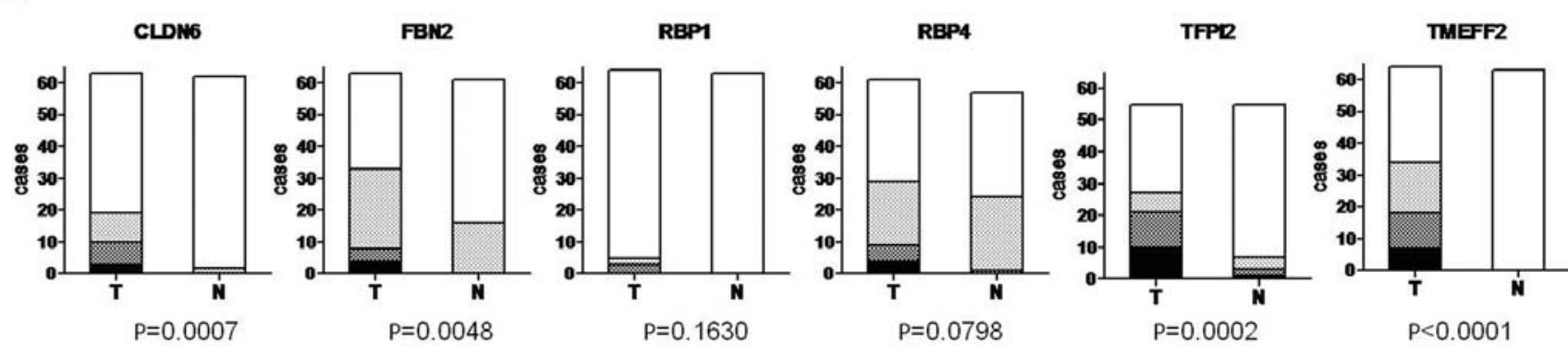

(b)
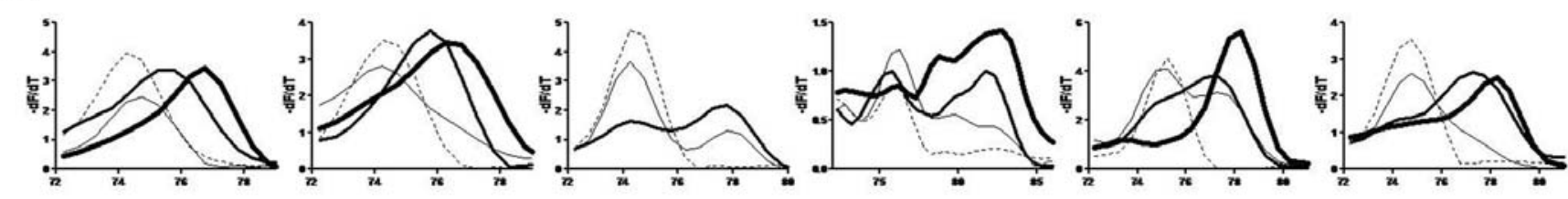

Figure 2. (a) The frequency and extent of methylation in esophageal squamous cell carcinoma resection specimens. Methylation of each gene was measured in cancer tissue $(\mathrm{T})$ and matched epithelium from the proximal margin of specimens $(\mathrm{N})$ resected for esophageal squamous cell carcinoma. The extent of methylation was graded from 3+ (black) to 0 (white) as described in the Materials and methods. The methylation in the tumor tissue was compared to that in the margin tissue by $\chi^{2}$ analysis. (b) Typical examples of melting curves from specimens with different extents of methylation are shown, with the bold line representing $3+$ methylation to the dotted line representing 0 .

on the RG3000 using the QuantiTect SYBR-Green PCR Kit (Qiagen). The PCR reaction was carried out in a $10 \mu 1$ reaction mixture consisting of $3 \mu \mathrm{l}$ of water, $5 \mu \mathrm{l}$ of $2 \mathrm{X}$ QuantiTect SYBR-Green PCR Master Mix, $0.5 \mu 1$ of each $10 \mu \mathrm{M}$ primers and $1 \mu 1$ of the first-strand cDNA. The primers and annealing temperatures are listed in Table I. For each sample the amount of the target and housekeeping gene hydroxymethylbilane synthase (HMBS) was determined using a calibration curve. The expression of the gene of interest was normalized to HMBS.

Statistical analysis. Statistical analysis was performed using GraphPad Prism version 4.02 for Windows (GraphPad Software, San Diego, CA, USA). The grade of methylation was compared between tissues using the $\chi^{2}$ test. Differences were considered significant when $\mathrm{P}<0.05$.

\section{Results}

Identification of methylated genes. We determined, in a panel of 5 different esophageal squamous cell carcinoma cell lines, the methylation status of 19 genes which we had previously shown to be significantly methylated in esophageal adenocarcinoma tissues and cell lines. Methylation was detected in one or more of the esophageal squamous cell carcinoma cell lines for CDH13, CLDN6, C16orf62, FBN2, FNBP1, ID4, RBP1, RBP4, TFPI2 and TMEFF2, but not for BNIP3, DCBLD2, MLF1, NRG1, PRDM2, RUNX3, TFAP2C, TIAM1, or VGLL3 (Table II).

To determine if methylation was associated with silencing of gene expression, mRNA expression was measured by qPCR in each of the aza-dC and vehicle treated esophageal squamous cell carcinoma cell lines. Treatment with aza-dC resulted in a reduction in methylation (Fig. 1a) and an increase in expression for CLDN6, FBN2, RBP1, RBP4, TFPI2 and TMEFF2 (Fig. 1b), suggesting an association between methylation and suppression of expression of these genes in the cell lines examined. However, there was not a correlation between methylation and altered expression for $\mathrm{CDH} 13$, C16orf62, FNBP1 and ID4 (data not shown).

Methylation in esophageal squamous cell carcinoma. Methylation of CLDN6, FBN2, RBP1, RBP4, TFPI2 and TMEFF2 was measured in tumor tissue and mucosa of matched proximal resection margins from patients who had had an esophagectomy for esophageal squamous cell carcinoma (Fig. 2). Each of the 6 genes was methylated more frequently in the tumors than the resection margins. No methylation of RBP1 or TMEFF2 was detected in any resection margin. The methylation grade was significantly greater in the tumor than in the epithelium of the resection margin for CLDN6, FBN2, RBP4 and TFPI2 ( $\mathrm{P}=0.0007$, $\mathrm{P}=0.0048, \mathrm{P}=0.0002$ and $\mathrm{P}<0.0001$, respectively).

\section{Discussion}

Esophageal cancer is one of the most common malignancies in the world, and with an overall 5-year survival of around $10 \%$ (2), one of the most lethal. Cancer develops in the setting of increased or decreased expression of critical genes. In addition to genetic alterations such as loss of heterozygosity and point mutation, DNA methylation at $\mathrm{CpG}$ islands is a common mechanism of gene inactivation in human carcinogenesis $(17,18)$. There are many reports of methylation changes in esophageal adenocarcinoma and its precursor lesions, with evidence for their role in tumor progression (19-21). Less is known about the mechanism of carcinogenesis and progression in esophageal squamous cell carcinoma, especially with regards to changes in methylation. Hence, identifying genes which are methylated in esophageal squamous cell carcinoma may increase our understanding of the underlying mechanisms in this cancer, 
and potentially lead to prognostic biomarkers or new therapeutic options.

In a previous study we had used expression profiling of an esophageal adenocarcinoma cell line before and after treatment with aza-dC to identify genes whose expressions were increased by this treatment, and so were potentially methylated. From this we identified 19 genes which were frequently methylated in esophageal adenocarcinoma, and not in normal esophageal epithelium $(9,10)$. The purpose of this current study was to determine if these genes were methylated in esophageal squamous cell carcinoma cell lines, and if so the frequency of their methylation in tissues.

Of the 19 genes which were methylated in esophageal adenocarcinoma, only 10 were methylated in at least 1 of the 5 esophageal squamous cell carcinoma cell lines which we examined. We demonstrated that demethylation of 6 of these methylated genes (CLDN6, FBN2, RBP1, RBP4, TFPI2 and TMEFF2) was associated with an increase in mRNA expression in the esophageal squamous cell carcinoma cell lines. This suggests that the methylation we measured was associated with gene silencing. Four genes (CDH13, C16orf62, FNBP1 and ID4) did not consistently show an inverse relationship between methylation and mRNA expression. This is in contrast to our finding that methylation of these same genes was associated with a reduction in mRNA expression in the esophageal adenocarcinoma cell lines (unpublished data). There are several possible explanations for the difference between the results from cell lines from the two different types of esophageal cancer. It is possible that we measured methylation in a region which is not responsible for repression of mRNA transcription. If this were so, it would mean that in the esophageal adenocarcinoma cell lines a region critical for repression was also concordantly methylated, but not in the esophageal squamous cell carcinoma cell lines. Another possibility is that the up-regulation of mRNA expression in the esophageal adenocarcinoma cell lines was secondary to the demethylation of other silenced genes, genes which are not methylated in the esophageal squamous cell carcinoma cell lines. Interestingly, the frequency of methylation of these three genes in the esophageal squamous cell carcinoma clinical specimen was higher than that in the matched normal epithelium, even though the increase was not statistically significant (data not shown).

Products of the claudin family of genes play an integral role in the formation and function of tight junctions (22), and their over- or under-expression has been reported in a number of cancers (22). The majority of studies have focused on CLDN1, CLDN3, CLDN4, CLDN7 and CLDN10. Little is known about the role of CLDN6 in cancer, but changes in the distribution pattern of claudins including CLDN6 in suprabasal epidermal cells were observed in a mouse model of skin tumorigenesis (23). Our findings of the methylation of CLDN6 suggest the possibility of its involvement in esophageal tumorigenesis.

This is the first report of the methylation of CLDN6, FBN2, RBP4, TFPI2 and TMEFF2 in esophageal squamous cell carcinoma. Interestingly, only these 5 genes were methylated in both major types of esophageal cancer, the other 13 genes in our study were methylated in adenocarcinoma but not squamous cell carcinoma. Future studies are required to correlate the silencing of these genes with clinicopathological parameters, including outcome, and to determine the relevance of this difference in methylation to the difference in biology of squamous cell carcinoma and adenocarcinoma.

\section{Acknowledgements}

We thank Dr Yutaka Shimada (Kyoto University) for the generous provision of the esophageal squamous cell carcinoma cell lines. This study was supported by a grant from the National Health and Medical Research Council of Australia (Project grant 275504).

\section{References}

1. Parkin DM, Bray F, Ferlay J and Pisani P: Global cancer statistics, 2002. CA Cancer J Clin 55: 74-108, 2005.

2. Sant M, Aareleid T, Berrino F, et al: EUROCARE-3: survival of cancer patients diagnosed 1990-94 - results and commentary. Ann Oncol 14 (Suppl. 5): V61-V118, 2003.

3. Botterweck AA, Schouten LJ, Volovics A, Dorant E and van Den Brandt PA: Trends in incidence of adenocarcinoma of the oesophagus and gastric cardia in ten European countries. Int J Epidemiol 29: 645-654, 2000.

4. Pohl $\mathrm{H}$ and Welch HG: The role of overdiagnosis and reclassification in the marked increase of esophageal adenocarcinoma incidence. J Natl Cancer Inst 97: 142-146, 2005.

5. Lord RV, Law MG, Ward RL, Giles GG, Thomas RJ and Thursfield V: Rising incidence of oesophageal adenocarcinoma in men in Australia. J Gastroenterol Hepatol 13: 356-362, 1998.

6. Vizcaino AP, Moreno V, Lambert R and Parkin DM: Time trends incidence of both major histologic types of esophageal carcinomas in selected countries, 1973-1995. Int J Cancer 99: 860-868, 2002.

7. Dawsey SM, Lewin KJ, Wang GQ, et al: Squamous esophageal histology and subsequent risk of squamous cell carcinoma of the esophagus. A prospective follow-up study from Linxian, P.R. China. Cancer 74: 1686-1692, 1994.

8. Bird A: The essentials of DNA methylation. Cell 70: 5-8, 1992.

9. Smith E, Nancarrow DJ, Pavey S, et al: Gene promoter methylation of ID4 And ARL4D in Barrett's esophagus and esophageal adenocarcinoma. Gastroenterology 130 (Suppl. 2): A565, 2006

10. Smith E, De Young NJ, Ruszkiewicz AR, Devitt PG, Jamieson GG and Drew PA: Novel aberrantly methylated genes in esophageal adenocarcinoma. Gastroenterology 132 (Suppl. 2): 322, 2007

11. Shimada $Y$, Imamura $M$, Wagata $T$, Yamaguchi $N$ and Tobe T: Characterization of 21 newly established esophageal cancer cell lines. Cancer 69: 277-284, 1992.

12. Tsunoda S, Okumura T, Ito T, et al: Significance of nerve growth factor overexpression and its autocrine loop in esophageal squamous cell carcinoma. Br J Cancer 95: 322-330, 2006.

13. Smith E, Drew PA, Tian ZQ, et al: Metallothionien 3 expression is frequently down-regulated in oesophageal squamous cell carcinoma by DNA methylation. Mol Cancer 4: 42, 2005.

14. Smith E, Bianco-Miotto T, Drew P and Watson D: Method for optimizing methylation-specific PCR. BioTechniques 35: 32-33, 2003.

15. Smith E, De Young NJ, Tian ZQ, et al: Methylation of TIMP3 in esophageal squamous cell carcinoma. World J Gastroenterol 14: 203-210, 2008

16. Chomczynski P: A reagent for the single-step simultaneous isolation of RNA, DNA and proteins from cell and tissue samples. BioTechniques 15: 532-534, 536-537, 1993.

17. Herman JG and Baylin SB: Gene silencing in cancer in association with promoter hypermethylation. N Engl J Med 349: 2042-2054, 2003 
18. Esteller M: Relevance of DNA methylation in the management of cancer. Lancet Oncol 4: 351-358, 2003.

19. Darnton SJ, Hardie LJ, Muc RS, Wild CP and Casson AG: Tissue inhibitor of metalloproteinase-3 (TIMP-3) gene is methylated in the development of esophageal adenocarcinoma: loss of expression correlates with poor prognosis. Int J Cancer 115: 351-358, 2005

20. Eads CA, Lord RV, Wickramasinghe K, et al: Epigenetic patterns in the progression of esophageal adenocarcinoma. Cancer Res 61: 3410-3418, 2001.
21. Schulmann K, Sterian A, Berki A, et al: Inactivation of p16, RUNX3, and HPP1 occurs early in Barrett's-associated neoplastic progression and predicts progression risk. Oncogene 24: 4138-4148, 2005

22. Kominsky SL: Claudins: emerging targets for cancer therapy. Expert Rev Mol Med 8: 1-11, 2006.

23. Arabzadeh A, Troy TC and Turksen K: Changes in the distribution pattern of Claudin tight junction proteins during the progression of mouse skin tumorigenesis. BMC Cancer 7: 196, 2007 